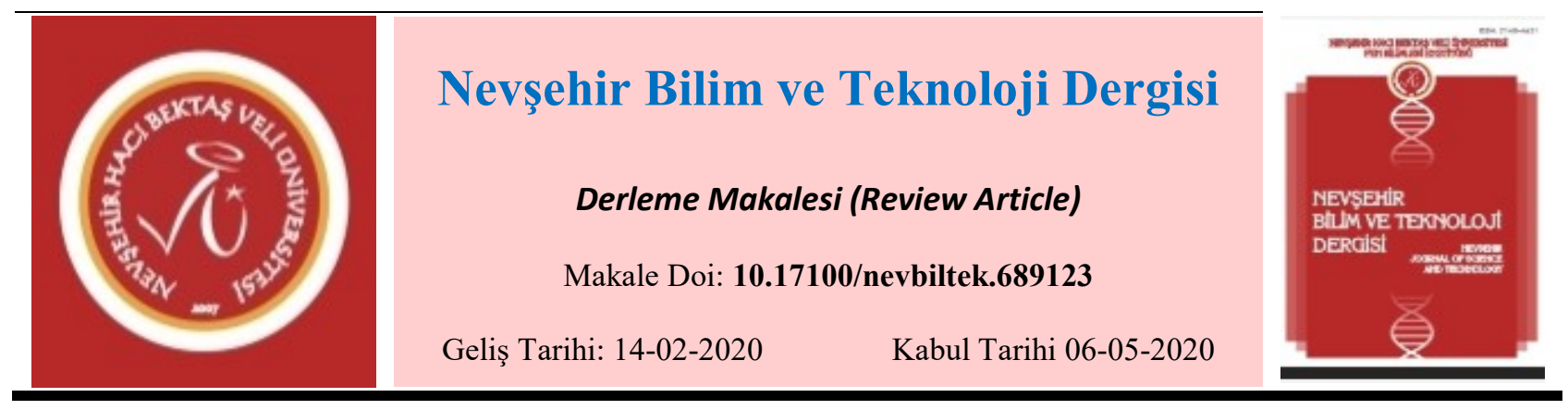

\title{
Çocuklarda Akılcı İlaç Kullanılmasının Önemi ve Ebeveynlere Öneriler *
}

\author{
Özlem ÇALIŞIR ${ }^{1 *}$, Zehra ÇALIŞKAN ${ }^{2}$ \\ ${ }^{I}$ Nevşehir Hacı Bektaş Veli Üniversitesi, Fen Bilimleri Enstitüsü, Hemşirelik Anabilim Dalı, Nevşehir \\ ORCID ID: /0000-0002-7541-131X \\ ${ }^{2}$ Nevşehir Hacı Bektaş Veli Üniversitesi, Semra ve Vefa Küçük Să̆lık Bilimleri Fakültesi, Çocuk Sağlı̆g ve Hastalıkları \\ Hemşireliği Anabilim Dall, Nevşehir \\ ORCID ID: 0000-0002-4726-5052 \\ $\ddot{O} \mathbf{z}$ \\ Çocuk sağlı̆̆ını olumsuz etkileyen faktörlerin başında enfeksiyon hastalıkları gelmektedir. Enfeksiyon hastalıklarının tedavisi de ilaç kullanımını \\ beraberinde getirmektedir. Son dönemlerde çoklu ilaç kullanımının artması, olumsuz ilaç reaksiyonlarına, ilaç etkileşimlerine ve artan maliyet \\ sorunlarına neden olduğundan "akılcı ilaç kullanımı" kavramı ön plana çıkmıştır. Dünya Sağlık Örgütü, ilaçların yarıdan fazlasının akılcı \\ kullanılmadığııı belirtmekte ve akılcı ilaç kullanımı'nı; hastaların klinik ihtiyaçlarına uygun, kendi bireysel gereksinimlerini karşılayan dozlarda, uygun \\ bir süre boyunca ve en düşük maliyetle ulaşması olarak tanımlamaktadır. Dünya çapında ilaçların güvenli, bilinçli ve etkili kullanımı, kamu sağlığının \\ yanı sıra, çocuk sağı̆̆̆ının iyileştirilmesinde de temel stratejilerden biri olarak karşımıza çıkmaktadır. Çocuklar dinamik bir büyüme-gelişme ve \\ olgunlaşma sürecindedirler. Çocuklarda bazı ilaçların kullanımına dair farmakokinetik/farmakodinamik verilerin sınırlı olması nedeniyle, ilaç güvenliği \\ ve akılcı ilaç kullanımı bu grupta daha da önem kazanmaktadır. Hemşirelerin, çocuklarda akılıı ilaç kullanımı konusunda ebeveynlere özellikle annelere, \\ eğitim ve danışmanlık vererek çocuk sağlığının iyileştirilmesine ve geliştirilmesine katkı sağlayacağı düşünülmektedir.
}

Anahtar Kelimeler: Akılcı İlaç Kullanımı; Ebeveyn; Çocuk; Hemşire

\section{The Importance of Rational Drug Use in Children: Recommendations to Parents}

\begin{abstract}
One of the main factors that negatively affect child health is infectious diseases and treatment of infectious diseases requires the use of medication. Because increased use of multiple drugs recently (poly-pharmacy) leads to adverse drug reactions and drug interactions, the concept of "rational drug use" has come to the fore as it causes increased cost problems. World Health Organization states that more than half of the drugs are not rationally used and defines Rational Drug Use as suitable for patients' clinical needs, received in doses that meet their individual needs, for a suitable period of time and at the lowest cost. Worldwide safe, conscious and effective use of drugs is one of the basic strategies in promoting public and child health. Being in a dynamic growth-development-maturation process of the children, limited pharmaco-kinetic / pharmaco-dynamic data on the use of certain drugs in children make drug safety and rational drug use more important for children. Nurses may contribute to improve child health by giving education and counselling to parents especially to mothers about rational drug use in children.
\end{abstract}

Keywords: Rational drug use; Parent; Child; Nurse

\footnotetext{
* Bu çalışma 2. Uluslararası 7. Ulusal Pediatri Hemşireliği Kongresi'nde poster bildiri olarak sunulmuştur. (27- 30 Kasım 2019, İzmir) "Sorumlu yazar e-mail: ozlemclsr@gmail.com
} 


\section{Giriş}

Birleşmiş Milletler (2018) verilerine göre; dünyada genel nüfus yaklaşık 7.7 milyar olup bu nüfusun \%25.7'sini 014 yaş grubu çocuklar oluşturmaktadır [1]. Ülkemizde ise Türkiye İstatistik Kurumu (TÜİK) 2018 verilerine göre; toplam nüfus 82 milyon olup, bu nüfusun \%23.4'ü 0-14 yaş grubu çocuklardan oluşmaktadır [2]. Nüfusun yaklaşık dörtte birini oluşturan yeni kuşakların sağlıklı yetişmeleri, toplumların gelişmesi için önemlidir. Çocukların sağlıklı yaşamaları ve iyi gelişmelerine yönelik her çaba, insanlığın gelecekteki refahı için yapılacak uzun dönemli yatırım olacaktır [3]. Bilinmektedir ki çocuk sağlığını olumsuz etkileyen pek çok faktör bulunmaktadır. Bu faktörler arasında, enfeksiyon hastalıkları, hava kirliliği, yetersiz su, tehlikeli kimyasallar-atıklar, radyasyon ve iklim değişikliği yer almaktadır [4]. Enfeksiyon hastalıklarının dünyada ve ülkemizde yüksek oranlarda görülmesi, çocukların hastaneye yatış ve ölüm nedenleri arasında ilk sırada yer alması, bu enfeksiyonların tedavisinde birçok ilacın kullanılmasını da beraberinde getirmektedir. Bununla birlikte çoklu sayıda ilaç kullanımının (Polifarmasi) giderek yaygınlaşması, bunun sonucunda istenmeyen ilaç reaksiyonları, ilaç etkileşimleri ve maliyetlerin artması akılıı ilaç kullanımını (AİK) ön plana çıkarmıştır $[5]$.

Bu derlemede, pek çok yönüyle yetişkinlere bağımlı olan çocuklarda, akılcı ilaç kullanımının önemi ve ebeveynlere verilecek önerilerin incelenmesi amaçlanmıştır.

\section{Materyal ve Metot}

Çalışma, literatür taranarak derleme şeklinde planlanmıştır.

\section{Akılcı İlaç Kullanımı}

Dünya çapında ilaçların güvenli, bilinçli ve etkili kullanımı; kamu sağlığının yanı sıra, çocuk sağlığının iyileştirilmesinde de temel stratejilerden biri olarak karşımıza çıkmaktadır [6]. Dünya Sağlık Örgütü, AİK’i; hastaların uygun ilaçlara, kendi bireysel gereksinimlerini karşılayan dozlarda, uygun bir süre boyunca ve en düşük maliyetle ulaşması şeklinde tanımlamaktadır [7]. İlaçların tedavi edici ve koruyucu olmasının yanında yan etkilerinin varlığı ve sağlık harcamalarında ciddi bir pay sahibi olması ilaç kullanımını daha da önemli kılmaktadır [8]. Bu denli önemli olan ilaç kullanımının çocuklarda da akılcı kullanılması gerekmektedir.

\section{Akılcı İlaç Kullanım İlkeleri}

İlaçların kullanılmasında göz önünde bulundurulması gereken temel ilkeler bulunmaktadır. Akılcı ilaç kullanımı ilkelerini oluşturan doğruların karşılanması elbette çocuk hastalar için de geçerlidir.

Akılcı İlaç Kullanımı ilkeleri;

- Belirlenen doğru ilacın,

- Doğru miktarda,

- Doğru uygulama yoluyla,

- Doğru zamanlamayla,

- Yeterli bilgilendirme yapılarak ve

- Maliyet uygunluğu da dikkate alınarak kullanılması ilkelerinin bütünüdür [9].

AİK ilkeleri iyi yönetilmezse; sağlık işgücü kaybı, ilaç tedavisinin kalitesinde azalma, artan morbidite/mortalite, tedavinin ekonomik ve sosyal maliyetinin artması, istenmeyen ilaç etkileri riski, temel ilaçlara ulaşabilirliğin azalması gibi birçok soruna sebep olabilmektedir [10, 11]. Ayrıca antimikrobiyal direnç gelişmesi de ilaçların akılcı kullanılmadığında karşımıza çıkan ciddi sorunlar arasında yer almaktadır [12]. Bu gibi sorunlar tüm ülkelerde görülmekle birlikte gelişmekte olan ülkelerde daha fazla görülmektedir. 
Nevşehir Bilim ve Teknoloji Dergisi (2020), 9(1) 32-38

\section{5. Çocuklarda Akılcı İlaç Kullanımının Önemi}

Büyüme ve gelişme; yetişkinlerde gözlenmeyen, çocuklarda gözlenen iki temel özelliktir [13]. Çocuklar, organların büyümesi ve fonksiyonlarının olgunlaşması ile ilişkili olarak ilerleyici gelişimsel değişiklikler gösterirler [14]. Bu süreçte hastalıklar çocuk sağlı̆̆ını olumsuz etkilemekte ve sağlı hizmeti alınmasını kaçınılmaz kılmaktadır. Hastanede yatarak ya da ayaktan tedavi şeklinde sağlık hizmeti alan çocuklarda, sağlık bakım sisteminin ilk önceliği hasta güvenliğini sağlayarak zarar vermemektir $[15,16]$. Hasta güvenliği açısından ilaç uygulamaları önemli yer tutmakta olup çocuklarda ve bebeklerde bu uygulamalar daha risklidir [17]. Özellikle bazı ilaçların pediatride kullanımına dair verilerin sınırlı olması, yaşa uygun ilaç formülasyonlarının azlığı, çocuklarda güvenli ilaç kullanımının önündeki engeller arasındadır [18].

Bütün yaş gruplarında, ortalama bir ilaç dozu hesaplanmakla birlikte her çocuk için ilacın dozu farklılık gösterebilmektedir [19]. Bu farklılıklar çocuklardaki metabolik kapasite değişiklikleri, eklem gelişimi, ilk 18 ayda böbrek ve gastrointestinal fonksiyon gelişimlerindeki farklılıklar olarak belirtilmektedir [20]. Çocuklarda fiziksel gelişim ile organların, taşıyıcıların ve enzimlerin olgunlaşmasını içeren fizyolojik gelişim, farmakokinetik parametrelerinde değişkenlik yaratabilmektedir. Bu yüzden farmakokinetik ölçümler; yaş, kilo veya vücut yüzey alanı olmak üzere büyüme ölçütleriyle ilgili olmalıdır [21].

Ağızdan alınan ilaçların emilimi için gastrointestinal sistemin önemli olduğu bilinmektedir. İlaçların midede emilmesi, bebeklik döneminden iki yaşına kadar geçen sürede, azalan mide Ph'ındaki değişikliklerden etkilenmektedir. Ayrıca çocukluk çağında bağırsakların özelliklerinde de değişiklik görülmektedir. Örneğin bağırsakta emilimi sağlayan yüzey alanının az olması ve bağırsak geçiş süresinin kısa olması ilaç emiliminin gecikmeli olduğunu gösterebilmektedir $[22,23]$.

İlaçların metabolitlere dönüştürülerek toksisitesinin düşürülmesinde özellikle karaciğer enzimleri aktif rol oynamaktadır. Ancak enzimler, yeni doğanlarda oluşmadığı gibi; 1-6 yaş grubunda ise enzimatik aktiviteler, bazı durumlarda yetişkinlere kıyasla daha yüksektir. Bu durum pediatri grubuna verilecek ilaç çeşidini ve dozunu önemli derecede etkilemektedir [24].

İlaçların vücuttan atılmasını sağlayan organlardan biri olan böbreklerin, bebeklerdeki fonksiyonları 6-12 ayda gelişerek yetişkin düzeyine ulaşabilir. Ayrıca ilaçların yarılanma ömrü de çocuklarda değişiklik gösterebilir [25]. Bebeklerde, glomerüler filtrasyon hızı yetişkinlerin \%25-30’u kadardır [26]. Yenidoğanlarda böbrek fonksiyonlarının olgunlaşmaması, vücutta değişmeyen ilaçların böbreklerle atılmasında düşük rol oynar [27].

Pediatrik farmakodinamik çalışmaların, farmakokinetik çalışmalardan daha az olması, pediatride doz hesaplama için ciddi bir sorun olarak görülmektedir [28]. Sonuçta farmakokinetik ve farmakodinamik araştırmaların önemi pediatrik alanda daha belirgin olarak karşımıza çıkmaktadır [29]. Bu yüzden çocuklarda ilaçların daha akılcı kullanılması önem arz etmektedir.

\section{6. Çocuklarda Güvenli İlaç Uygulaması İçin Hemşirenin Rolleri}

Hemşirelik Yönetmeliği'ne göre (2010) hemşirelerin; birey, aile, grup ve toplumun sağllğının geliştirilmesi, korunması ve yaşam kalitesinin artırılması amacıyla güvenli ve sağlıklı bir çevre oluşturarak, bu çevrede eğitim, danışmanlık, iş birliği ve iletişimi sağlama rolleri bulunmaktadır [30]. Hemşireler; kurum dışında da toplumu bilgilendirme, ailelere rehberlik/danışmanlık yapma gibi sorumlulukları da üstlenmektedirler [31]. Dolayısıyla hemşireler, ebeveynlerin akılcı ilaç kullanım tutumlarını olumlu etkileyebilir, yanlış bilgileri doğruları ile değiştirerek toplumun yararına katkı sağlayabilirler.

Çocuklarda başarılı ilaç uygulamaları; onların yaş, yüzey alanı ve vücut ağırlığına göre ilaçların hazırlanmasını ve güvenli uygulanmasını içerir. Çocuklarda güvenli ilaç uygulaması için hemşirenin rolleri şu şekilde belirtilmektedir.

$\checkmark$ Hekimin istemi yoksa hemşirenin kendi başına ilaç uygulamaması, 
Nevşehir Bilim ve Teknoloji Dergisi (2020), 9(1) 32-38

$\checkmark$ Hekim isteminin verildiği zamanın kontrol edilmesi, istemlerin mutlaka yazılı olması,

$\checkmark$ Hemşirelerin ilaçların endikasyonları, kontrendikasyonları, komplikasyonları, ilaç-ilaç, ilaç-besin etkileşimleri konularında bilgi sahibi olmas1,

$\checkmark$ Hastaneye yatışı kabul edilen çocukların ağırlığının ölçülmesi, ilaç alerji varlığı, daha önce kullandığı ilaçların sorgulanarak kayıt altına alınması,

$\checkmark$ Çocuk için istem edilen dozların güvenli aralıkta olup olmadığının kontrol edilmesi,

$\checkmark \quad$ Flakonların kuru toz hacimleri olabileceğinden, doz hesaplanırken bu durumun göz önüne alınması,

$\checkmark$ Doz hesaplamalarının mutlaka iki hemşire tarafından yapılması, alışık olunmayan dozların doğrulanması,

$\checkmark$ İlaç uygulamalarında 8 D (Sekiz doğru) ilkesine dikkat edilmesi (Doğru ilaç, doğru doz, doğru çocuk, doğru yol, doğru zaman, doğru yaklaşım, doğru bilgilendirme, doğru kayıt),

$\checkmark$ Şekil ve isim olarak benzeyen ilaçların farklı yerlerde dikkatli muhafaza edilmesi,

$\checkmark$ İlaçları hazırlarken dikkat dağıtacak faktörleri, uyaranları en aza indirmeleri, ilaçların sessiz sakin bir ortamda hazırlanmas1,

$\checkmark$ İlaçların çocuğa verilmeden önce, çocuk ve aileye terapötik iletişimle açıklama yapılması,

$\checkmark \quad$ Pediatrik ilaç bilgisi ve uygulamalarına yönelik güncel yeniliklerin takip edilmesi önerilmektedir $[32,33]$.

\section{7. Çocuklarda İlacı Doğru Kullanmak İçin Ebeveynlere Öneriler}

Hemşirelerin; ebeveynlerin akılcı ilaç kullanım tutumlarını ve bu tutumlarını etkileyen faktörleri belirlemesi önemlidir. Böylelikle ebeveynlerin ilaç kullanımında yanlış bilgi/tutumlarının farkına vardırılmasıyla çocuk sağlığının iyileştirilmesine katkı sağlanabilir.

Çocuklarda ilacı doğru kullanmada ebeveynlere öneriler şu şekilde özetlenebilir:

$\checkmark$ İlaçların hekim tavsiyesi olmadan, reçetesiz olarak alınıp kullanılmaması,

$\checkmark \quad$ İlacın dozu bireysel farklılıklar göstereceğinden hekimin önerdiği dozajın kullanılması,

$\checkmark$ İlacın hekimin önerdiği süre kadar kullanılması,

$\checkmark$ Çocuklarda doz atlamamaya ve hekimin önerdiği şekilde almaya özen gösterilmesi,

$\checkmark$ İlacın içinde bulunan kullanma talimatlarının (prospektüs) ve ilacın kutusunun, ilaç bitene kadar saklanması,

$\checkmark$ İlaçların mutlaka, çocuğun sandalye ve taburelerle ulaşamayacağı yerde ve prospektüsünde yazıldığı şekilde 1şıktan ve nemden korunarak muhafaza edilmesi,

$\checkmark$ Buzdolabında saklanması gereken ilaçların buzlukta saklanmaması ve dondurulmaması,

$\checkmark$ Son kullanma tarihi geçen ya da daha önceki tedaviden arta kalan ilaçların kullanılmaması ancak çöpe de atılmaması, tıbbi atıkların bulunduğu çöplere ya da ilaç geri dönüşüm kutularına atılmak üzere eczaneye veya hastaneye birak1lmas1,

$\checkmark$ Çocukların yanında ya da ulaşabileceği yerde ilaç bırakarak kısa süreliğine bile olsa başka odaya geçilmemesi,

$\checkmark$ Karanlık ortamda; ilaçların karışabileceği, verilen ilacın dökülebileceği, ilacı yutup yutmadığının anlaşılamayacağı düşüncesiyle, çocuklara karanlıkta ilaç içirilmemesi,

$\checkmark$ Çocuklarda merak uyandırma/özendirebilme düşüncesiyle, yetişkin hastaların çocukların yanında ilaçlarını almamas1,

$\checkmark$ Çocuklara boş ilaç kapları, kutuları, enjektörleri verilmemesi, onları bir gıda ya da oyuncak gibi algılamalarının önlenmesi,

$\checkmark$ Bazı ilaçların aç ya da tok alınması gerekebildiğinden, bu durum eczacı/hekim/hemşireye danışıldıktan sonra ilacın alınması,

$\checkmark$ İlaç uygulama öncesi yaş dönemlerine uygun olarak çocuklara/ebeveynlere açıklama yapılması, 
Nevşehir Bilim ve Teknoloji Dergisi (2020), 9(1) 32-38

$\checkmark \quad 5$ yaş altı çocukların tabletleri yutmada güçlük yaşayabileceği göz önünde bulundurularak, tabletlerin kırılarak az miktarda su ile eritilerek verilmesi,

$\checkmark$ Bebek ve çocuklar ilaçların sıvı formunu alabileceğinden, $5 \mathrm{ml}$ altındaki ilaç dozları için oral enjektörlerin kullanılması,

$\checkmark$ Sıvı hale getirilmiş ilaçların iğnesi çıkarılmış enjektör ile de verilebilmesi, enjektörün ucunun bebeğin/çocuğun ağzının yan tarafına yerleştirilerek ilacın yavaşça verilmesi,

$\checkmark$ Çocuğun/bebeğin yutmasının gözlenmesi ve başının yüksekte olacak şekilde pozisyonunun ayarlanması,

$\checkmark$ Çocuk ilacı tükürürse ya da hemen kusarsa ilacın tekrar verilmesi, $30 \mathrm{dk}$.'dan sonra kusarsa tekrar verilmemesi,

$\checkmark$ İlaçların, çocuk/bebek sakinken verilmesi,

$\checkmark \quad$ İlaçların süt ya da diğer besin ürünleri (asitli içecekler, meyve suyu, greyfurt suyu, kolalı içecekler, yoğurt) ile karıştırılarak verilmemesi,

$\checkmark$ Çocuklara ağızdan ilaç verilirken, tadı konusunda dürüst olunması,

$\checkmark$ İlaçların, kendi kutusundan çıkan ölçekleri ile verilmesi,

$\checkmark$ Çocuklara nebülizatör ile buhar uygulamasında; yüzüne uygun maskeler tercih edilmesi, maskelerin çocuğun yüzünden uzak tutulmaması ve çocuğun ağız solunumu yapmasının önerilmesi,

$\checkmark$ Buhar ile verilen ilacın miktarı 2,5 ml'den az ise 2-4 cc olacak şekilde \%0.9 izotonik su ile sulandırılması,

$\checkmark$ Buhar uygulamalarında özellikle antibiyotik veya steroid kullanılmışsa, ağızda mantar enfeksiyonu oluşumunu engellemek için işlem sonrası çocuğun yüzünün yıkanması ve duru su ile ağzının çalkalanmasının önerilmesi,

$\checkmark$ Göze ilaç damlatmada, çocuğun sırt üstü yatırılıp omuz ve boynun yastıkla desteklenmesi ve ilacın direk kornea üzerine değil konjektival keseye damlatılması,

$\checkmark \quad$ Kulağa ilaç damlatmada, çocuğun sırt üstü yatırılması işlem yapılacak kulağın üstte gelecek şekilde başının çevrilmesi ve çocuk 3 yaşından küçükse kulak kepçesinin aşağı ve geriye doğru, 3 yaşından büyükse kulak kepçesinin yukarı ve geriye doğru çekilerek ilacın damlatılması, uygulama öncesi ilacın oda ısısına gelmesinin sağlanması,

$\checkmark$ Rektal ilaç uygulanmasında, çocuğun dışkılamasından sonra ilacın uygulanması, eldiven giyilmesi ve supozituvarın (fitil) kolay girmesi için sıcak su ile ıslatılması, bebeklerde sırtüstü yatırılıp bacakların fleksiyona (bükülmesi) getirilmesi, büyük çocuklarda ise sol yan yatırılıp sağ bacağın karnına çekilmesinin sağlanması,

$\checkmark$ Tüm ilaç uygulamalarında, ilaç alımı sonrası yan etkiler açısından çocukların takip edilmesi önerilmektedir [3237].

\section{Sonuç}

Ülkemizde, akılcı ilaç kullanılmasına yönelik Sağlık Bakanlığı'nın yaptığı birçok girişime rağmen, yapılan çalışmalarda ebeveynlerin, çocuklarına reçetesiz ilaç kullanma, verilen ilaçları hekimin belirttiği süre kadar kullanmama, ilacı kutusundan çıkan ölçek ile vermeme, tedavi bittikten sonra kalan ilaçları saklama, ilaçları besin öğeleri ile birlikte verme gibi akılcı olmayan ilaç kullanımına yönelik tutumlarının olduğu görülmektedir [38-40]. Bu yüzden de toplumun her kesimi ile iç içe olan hemşirelerin, çocuklarda akılcı ilaç kullanımına yönelik ebeveynleri özellikle anneleri eğitim ve danışmanlık vererek desteklemeleri önerilmektedir [41].

\section{Kaynaklar}

[1] United Nations ESCAP, www.unescap.org/stat/data/

[2] Türkiye İstatistik Kurumu, http://tuik.gov.tr/UstMenu.do?metod=temelist

[3] Öztek Z., Kubilay G., “Toplum Sağlığı Hemşireliği”” Palme Yayıncılık, 130s, Ankara, 2005 
[4] World Health Organization "Don't pollute my future! The Impact Of The Environment On Children's Health" $2015 \mathrm{http} / / / \mathrm{www}$.who.int/ceh/publications/don-t-pollute-my-future/en/

[5] Reppe L. A., Spigset O. Schjott, J., "Drug information services today: current role and future perspectives in rational drug therapy" Clinical Therapeutics, 38 (2), 414-421, 2016

[6] Rieder M., "Do we prescribe medicines rationally?" Archives of Disease in Childhood, 100, 958-959, 2015

[7] World Health Organization (WHO), "The Rational Use Of Drugs" Report Of The Conference Of Experts, Nairobi, 25-29 November 1985. Geneva 1987.

[8] İlaç Endüstrisi İşverenler Sendikası (İEİS), “Türkiye İlaç Sektörü 2017 Raporu”, 4-29, 2018 http://ieis.org.tr/ieis/tr/sektorraporu2017

[9] Korkmaz Bulut. C., Özel A. F., "Sağlık tüketicilerinin akılcı ilaç kullanımı tutumlarının değerlendirilmesi” Sağllk Yönetim Dergisi, 2 (1), 79-109, 2018

[10] Amin A., Khan M. A., Azam S. M. F., Haroon U., "Review of Prescriber Approach Towards Rational Drug Practice in Hospitalised Patients" Journal of Ayub Medical College Abbottabad, 23 (1), 19-22, 2011

[11] Afriyie D., Tetteh R., "A description of the pattern of rational drug use in Ghana Police Hospital" International Journal Of Pharmacy And Pharmacology, 3 (1), 143-148, 2014

[12] World Health Organization "Antimicrobial Resistance Global Report On Surveillance", 1-256s, 2014. http://apps.who.int/medicinedocs/documents/s21405en/s21405en.pdf

[13] Marsot A., "Pharmacokinetic variability in pediatrics and intensive care: Toward a personalized dosing approach” Journal of Pharmacy \& Pharmaceutical Sciences, 21 (1), 354-362, 2018

[14] Beaumais A., Jacqz-Aigrain E., "Pharmacogenetics: Applications to pediatric patients" Advances in Pharmacology, 83, 191-215, 2018

[15] Törüner E., Erdemir F., "Pediatrik hastalarda ilaç uygulama hatalarının önlenmesi” Hacettepe Üniversitesi Sağllk Bilimleri Fakültesi Hemşirelik Dergisi, 63-71, 2010

[16] Gök D., Sarı Yıldırım H., "Pediatride ilaç hataları ve hata bildirimi” İzmir Dr. Behçet Uz Çocuk Hastalıkları Dergisi, 6 (3), 165-173, 2016

[17] Manav G., Başer S., "Çocuk hemşirelerinin ilaç hatası yapma durumları ve eğilimlerinin incelenmesi”" Gümüş̧ane Üniversitesi Sağllk Bilimleri Dergisi, 7 (3), 41-49, 2018

[18] Frattarelli D. A., Galinkin J. L., Green T. P., Johnson T. D., Neville K. A., Paul I. M., Van Der Anker J. N., "Off-label use of drugs in children" Pediatrics, 133 (3), 563-567, 2014

[19] Mahmood I., "Dosing in children: A critical review of the pharmacokinetic allometric scaling and modelling approaches in paediatric drug development and clinical settings" Clinical Pharmacokinetics, 53, 327-346, 2014

[20] Filler G., Bravo M., "Appreciating the need for greater understanding of the pharmacokinetics of drugs in children and adolescents" Pediatric Transplantation, 22 (8), 1-2, 2018

[21] Holford N., Heo Y. A., Anderson B., "A pharmacokinetic standard for babies and adults" Journal of Pharmaceutical Sciences, 102, 2941-2952, 2013

[22] Marsot A., Boulamery A., Bruguerolle B., Simon N., "Population pharmacokinetic analysis during the first 2 years of life" Clinical Pharmacokinetics, 51 (12), 787-798, 2012

[23] Lu H., Rosenbaum S., "Developmental pharmacokinetics in pediatric populations" The Journal Of Pediatric Pharmacology And Therapeutics, 19 (4), 262-276, 2014 
[24] Dotta A., Chukhlantseva N., "Ontogeny and drug metabolism in newborns" The Journal of Maternal-Fetal \& Neonatal Medicine, 25 (sup4), 75-76, 2012

[25] Pala Z., Baktır G., “Çocuklarda akılcı ilaç kullanımı” Türk Eczacılar Birliği Yayını/Meslek İçi Sürekli Ĕgitim Dergisi, 60-68s. http://e-kutuphane.teb.org.tr/pdf/mised/kasim05/9.pdf

[26] Debotton N., Dahan A., "A mechanistic approach to understanding oral drug absorption in pediatrics: an overview of Fundamentals” Drug Discovery Today, 19 (9), 1322-1326, 2014

[27] Batchelor H. K., Marriott J. F., "Paediatric pharmacokinetics: Key considerations" British Journal of Clinical Pharmacology, 79 (3), 395-404, 2015

[28] Anderson B. J., Holford N. H., "Understanding dosing: children are small adults, neonates are immature children" Archives of Disease In Childhood, 98 (9), 737-744, 2013

[29] Barker C. I. S., Standing J. F., Kelly L. E., Faught H. L., Needham C. A., Rieder M., Wildt S., Offringa M., "Pharmacokinetic studies in children: Recommendations for practice and research" Archives Of Disease In Childhood, 103, 695-702, 2018

[30] T.C. Sağlık Bakanlığı, “Hemşirelik Yönetmeliği”, https://www.saglik.gov.tr/TR,10533/hemsirelikyonetmeligi.html

[31] Şanlı D., Öztürk C., “Annelerin çocuk yetiştirme tutumlarını etkileyen etmenlerin incelenmesi” Dokuz Eylül Üniversitesi Buca Ĕ̈itim Fakültesi Dergisi, 32, 31-48, 2012

[32] Törüner E. K., Büyükgönenç L., “Çocuk Sağlı̆̆ı Temel Hemşirelik Yaklaşımları” Göktuğ Yayıncılık, 339-345s, Ankara, 2012

[33] Çavuşoğlu H., “Çocuk Sağlığ1 Hemşireliği 1-2.” Sistem Ofset Matbaacılık, 251-268s, Ankara, 2013

[34] Akıcı A., 'Çocuklarda İlaç Kullanırken Nelere Dikkat Edilmelidir?' Akıcı A. Ed. Sosyal Güvenlik Kurumu Başkanlı̆̆l, Ankara: SGK Yayın No:93, 44-46, 2013

[35] Aktay G., “Doğru ve etkili ilaç kullanımı”, Koruyucu Sağlık Rehberi, Yakıncı C., Yeşilada E. Ed. Türk Eczacılar Birliği Eczacılık Akademisi, 356-361s, Ankara, 2013

[36] T.C. Sağlık Bakanlı̆̆ı “Akılcı İlaç Kullanımı Ulusal Eylem Planı 2014-2017 www.akilciilac.gov.tr/wpcontent/uploads/2014/11/aik-ulusal-eylem plani.pdf

[37] Pekcan S., “Çocuklarda inhaler tedavi uygulamaları” Solunum Dergisi, 14(2), 63-72, 2012

[38] Akıcı N., Gelal A., Gürbüz T., Ceran Ö., Akıcı A., "Hastaneye başvuru öncesinde çocuklarda ilaç kullanımının araştırılması" The Anatolian Journal of Clinical Investigation, 9 (1), 10-18, 2015

[39] Tosun N., Tosun M., Gökalp Y., "İkinci basamak sağlık kurumuna başvuran hastaların akılcı ilaç kullanım durumlarının belirlenmesi” Sosyal Bilimler Dergisi, 5 (27), 370-385, 2018

[40] Ocan M., Bbosa G. S., Waako P., Ogwal-Okeng J., Obua C., "Factors Predicting Home Storage of Medicines in Northern Uganda" BioMed Central Public Health, 14 (650), 1-7, 2014

[41] Yılmaz F., Arıkan D., Baklacı Ö., Bilmez A., Bülbül D., "0-2 yaş dönem çocuğu olan annelerin oral ilaç kullanım davranışlarının incelenmesi” Anadolu Hemşirelik ve Să̆lık Bilimleri Dergisi, 16 (2), 82-88, 2013 